\title{
25 Research Square \\ Deletion of Dnm1 Gene In Mitochondria Lead To The Changes of Cell Dynamics and Energy Metabolism In Fission Yeast
}

\section{Xiumei Tan}

China West Normal University

\section{Xiang Ding}

China West Normal University

Rongmei Yuan

China West Normal University

Yiling Hou ( $\nabla$ starthlh@126.com )

China West Normal University https://orcid.org/0000-0001-9437-1037

\section{Research Article}

Keywords: mitochondria, Dnm1 gene, cell cycle, dynamics, mitosis

Posted Date: August 20th, 2021

DOI: https://doi.org/10.21203/rs.3.rs-695748/v1

License: (c) (i) This work is licensed under a Creative Commons Attribution 4.0 International License. Read Full License 


\section{Abstract}

Mitochondria are dynamic organelles that undergo cycles of fission and fusion. The major mitochondrial fission protein is dynamin-related Drp1 GTPase (Dnm1 in yeast). The effects of Dnm1 gene deletion on cell dynamics and energy metabolism during mitosis were studied in Schizosaccharomyces pombe. Dnm1 gene deletion can lead to slow growth, abnormal sporulation, abnormal number and length of interphase microtubules of Schizosaccharomyces pombe. The deletion of Dnm1 gene can also affect the spindle growth speed and growth time of metaphase and anaphase, and affect the spindle fluorescence intensity of prophase and metaphase. At the same time, the structure and dynamics of the spindle microtubules of $D n m 1 \Delta$ are also different. The statistics of spindle length showed that there was delayed spindle fracture in Dnm1 $\Delta$ Cells. Two different chromosome behaviors, normal and lagged, were observed by living cell imaging. The analysis of coenzymes, intermediates and energy in energy metabolism showed that there were some abnormalities after Dnm1 gene deletion, including coenzyme defects, intermediate metabolite defects and ATP production defects.

\section{Introduction}

Mitochondria are dynamic organelles that undergo a cycle of division and fusion (Francy et al. 2015; Jourdain et al. 2010; Delerue et al. 2019; Lackner. 2014; Bertholet et al. 2016 ). Therefore, the regulatory balance between division and fusion seems to be crucial for the control of mitochondrial morphogenesis (Chen et al. 2014). In fact, the dynamics of mitochondrial division and fusion and the proteins that control these processes (from yeast to human) are essential. Their disorders are associated with serious human diseases, including Beckwith-Wiedemann syndrome, Charcot-Marie-Tooth disease type 6, CharcotMarie-Tooth disease axonal type 2S, neurodegenerative diseases, multiple symmetric lipomatosis and microcephaly (Gao et al. 2017; Burté et al. 2014; Sajic. 2014; Zhao et al. 2012; Kim et al. 2019; Huber et al. 2013; Sheffer et al. 2016; Rousset et al. 2012; Berkovic et al. 1991) .

The main dynamic related protein of mitochondria is Drp1 GTPase (Dnm1 in yeast) (Naumann et al. 1992; Chang et al. 2010; Bleazard et al. 1999). The structure of GTPase in dynamin family is similar, including GTP binding region, intermediate region and GTPase effect region, but the function is different. It is reported that the mitochondria in $D n m 1 \Delta$ present as highly interconnected tubules forming a network structure or thick bundle like tubules, which indicates that $D n m 1$ is necessary for mitochondrial fission (Mears et al. 2011). Dnm1 mediates mitochondrial fission at interphase growth and at cell division during mitosis (Karren et al. 2005). In Saccharomyces cerevisiae, Dnm1p (called DLP1, Drp1, or dvlp1 in other species) is captured by fis $1 p /$ mdv2p together with net2p / gag3p / mdv1p / fis $2 p$ and mediates mitochondrial division (Tieu et al. 2002). In addition, the repetitive roles of Dnm1 and vps 1 in cell cycle regulated peroxisome biogenesis were also reported (Kuravi et al. 2006).

Cell replication involves a series of highly regulated and evolutionarily conserved complex events, known as "cell cycle" (Syrovatkina et al. 2013). Cell cycle abnormalities have a serious impact and may lead to cancer growth. A detailed understanding of the cell cycle and its regulation can identify other targets for 
cancer treatment. Schizosaccharomyces pombe (fission yeast) is a single celled organism, easy to genetic operation, with many cell cycle characteristics similar to metazoan cells (Dumont et al. 2009). It is an important model organism for studying cell cycle and checkpoint control (Goshima et al 2010). In this paper, the effect of $D n m 1$ gene deletion on cell mitotic dynamics was studied by using the model of Schizosaccharomyces pombe (fission yeast).

\section{Materials And Methods}

\section{S. pombe strains construction}

Yeast genetics was carried out as previously described (Forsburg et al. 2006), and yeast strains were created by random spore digestion. Yeast culture media were purchased from For Medium (Norfolk, UK). All strains used in this study are listed in Table 1.

Table 1

List of strains

\begin{tabular}{|lll|}
\hline Strain & Genotype & Figure \\
\hline PT.286 & Wt: ade6.M210 leu1.32 ura4.D18 h- & Figure 1-7 \\
\hline PT.287 & Wt: ade6.M210 leu1.32 ura4.D18 h+ & Figure 1-7 \\
\hline PT.917 & Wt: mC-Atb2: leu1.32 h- & $\backslash$ \\
\hline PT.2167 & Wt: Hht2-GFP: ura4-D18 h+ & Figure 1-7 \\
\hline HY 4 & Wt: Hht2-GFP: ura4.D18: mC-Atb2: leu1.32 KanR h- & Figure 1-7 \\
HY 5 & Wt: Hht2-GFP: ura4.D18: mC-Atb2: leu1-32 KanR h+ & Figure 1-7 \\
HY 1933-1 & Dnm1 $1:$ KanR.h- & Figure 1-7 \\
HY 1933-2 & Dnm1 $\Delta:$ KanR.h+ & Figure 1-7 \\
HY 1933-4 & Dnm1 $\Delta:$ Hht2-GFP: ura4-D18: mC-Atb2: leu1.32 KanR h- & Figure 1-7 \\
\hline HY 1933-4 & Dnm1 $\Delta:$ Hht2-GFP: ura4-D18: mC-Atb2: leu1.32 KanR h+ & Figut \\
\hline
\end{tabular}

\section{Microscopy}

Living cell imaging was performed at room temperature $25^{\circ} \mathrm{C}$. A spinning-disc confocal microscope with a Nikon PlanApo 100×/1.40 NA objective and the Photometrics CoolSNAP HQ2 CCD camera was used (Tran et al. 2004). MetaMorph 7.5 (http://www.moleculardevices.com) was used to collect and process all images. In order to obtain high temporal resolution, images were acquired at $300-500 \mathrm{~ms}$ exposure for GFP/mCherry, 60 -sec intervals, 90 min total time for 11 optical sections of $0.5 \mu \mathrm{m}$ spacing (Rongmei et al. 2020).

\section{Analysis method of energy metabolites}


The cells were cultured in YE5S medium, $25^{\circ} \mathrm{C}$ for 3 days. The cells were washed three times with cold PBS, collected in a $1.5 \mathrm{ml}$ centrifuge tube, frozen in liquid nitrogen, stored at $-80^{\circ} \mathrm{C}$, after centrifuged with $3000 \mathrm{~g}$ at $4{ }^{\circ} \mathrm{C}$ for 5 minutes. The collected cells were sent to Shanghai applied protein Technology Co. Ltd. to be analyzed for metabonomics by LCMS.

\section{Data analysis}

All data were expressed by mean $\pm S D$, and the significant difference between the experimental group and the control group was statistically analyzed by one-way ANOVA using SPSS 17 software. ${ }^{*} P<0.05$, represents a significant difference, and $* * P<0.01$ represents an extremely significant difference, respectively.

\section{Results}

The effect of Dnm1 gene deletion on the cell growth, morphology and number of microtubule and ascospores

The results of cell growth showed that there was no significant difference between the wild type and Dnm $1 \Delta$ Cells at $25^{\circ} \mathrm{C}$ for $0-6$ hours. After 6 hours, the growth rate of wild type was faster than that of Dnm1 $1 \Delta$. After 12 hours, the $\mathrm{OD}_{595}$ of wild type and Dnm1 $1 \Delta$ cells reached 0.625 and 0.202 , respectively, which is very different from the wild-type cells (Fig. 1A). The results showed that $D n m 1$ gene deletion could slow down the growth of Schizosaccharomyces pombe. The number of ascospores produced by wild type and Dnm1 1 cells as shown in (Figs. 1B and 1C). The results showed that $99.20 \pm 0.00 \%, 0.53 \pm$ $0.31 \%$ and $0.27 \pm 0.31 \%$ of wild-type cells produce four, three and two ascospores $(n=1500)$, respectively, while $95.07 \pm 0.81 \%, 4.73 \pm 0.64 \%$ and $0.00 \pm 0.00 \%$ of $D n m 1 \Delta$ cells produce four, three and two ascospores, respectively, in which there had extremely significant difference $(P<0.01)$ in the number of four and three ascospores (Figs. 1B and 1C). There was no significant difference in the morphology of ascospores between wild type and $D n m 1 \Delta$ cells, which showed that $D n m 1$ gene and its encoded protein had an effect on the production of sporozoites, but had no effect on the morphology of sporozoites. The results of the number of microtubules showed that $31.67 \pm 2.89 \%, 55.00 \pm 5.00 \%$, and $13.33 \pm 5.77 \%$ of wild-type cells have three, four and five microtubules, respectively, while $13.33 \pm 2.88 \%, 63.34 \pm 5.77 \%$ and $23.33 \pm 7.63 \%$ of $D n m 1 \Delta$ cells have three, four, five microtubules, respectively, in which there had extremely significant difference $(P<0.01)$ in the number of three microtubules between wild type and Dnm $1 \Delta$ cells (Figs. 1D and 1E). The statistical results of microtubule length in mitotic interphase cells showed that microtubule length of wild type and Dnm $1 \Delta$ cells were $5.13 \pm 1.44 \mu \mathrm{m}$ and $5.97 \pm 2.14 \mu \mathrm{m}$, respectively, which had extremely significant difference in the two groups (Fig. 1F). The results showed that the deletion of $D n m 1$ gene resulted in the increase of microtubule length. The results of microtubule dynamics of wild type cells and Dnm $1 \Delta$ cells during mitotic interphase showed that the MT (Microtubule) of wild-type cells grew at $1.50 \pm 0.56 \mu \mathrm{m} / \mathrm{min}(n=10)$ and shrunk at $1.40 \pm 0.30 \mu \mathrm{m} / \mathrm{min}(n=10)$, and the MT dwell time was $1.21 \pm 0.21 \mathrm{~min}(\mathrm{n}=10)$. In contrast, the MT of Dnm1 $\Delta$ cells grew at $1.57 \pm 0.85$ $\mu \mathrm{m} / \mathrm{min}(\mathrm{n}=10)$ and shrunk at $1.21 \pm 0.47 \mu \mathrm{m} / \mathrm{min}(\mathrm{n}=10)$, and the MT dwell time was $1.16 \pm 0.31 \mathrm{~min}$ 
$(n=10)$ (Figs. 1G-1J). The results indicated that there were no different of microtubule dynamics during mitotic interphase between wild type and $D n m 1 \Delta$ cells.

\section{The effect of Dnm1 gene deletion on spindle and cell length during cell mitosis}

In the process of mitosis, SPBs (spindlepoly body) organize the mitotic spindle for chromosome separation. The mitotic spindle has three different elongation stages corresponding to different mitotic stages. The SPBs also organize the astral MTs, and its function is similar to interphase MTs in nuclear and spindle positioning. The mC-Atb2 (a-tubulin) and Hht2-GFP (Nucleosomal histone) were used as a detection signal for prophase and metaphase to explore spindle elongation and chromosome segregation dynamics in cell mitosis of wild-type cells and $\operatorname{Dnm} 1 \Delta$ cells. Wild-type cells exhibited typical three-phase spindle elongation kinetics, corresponding to prophase (phase I), metaphase (phase II), and anaphase A (chromatid separation) and B (spindle elongation) (Fig. 2A). The statistics of spindle length showed that there was delayed spindle fracture in $D n m 1 \Delta$ cells (Figs. 2A-2E). The final time from spindle formation to fracture was $34.60 \pm 4.03 \mathrm{~min}$, while that was $42.40 \pm 4.13 \mathrm{~min}$ in $D n m 1 \Delta$ cells, which had extremely significant difference $(P<0.01)$ in the two groups. The final spindle length was $11.93 \pm 0.87 \mu \mathrm{m}$ in wild type cells, while that was $13.56 \pm 1.73 \mu \mathrm{m}$ in Dnm1 $\Delta$ cells, which also had extremely significant difference $(P<0.01)$ (Figs. 2E). The final time from spindle formation to fracture was $34.60 \pm 4.03 \mathrm{~min}$, while that was $42.40 \pm 4.13 \mathrm{~min}$ in $D n m 1 \Delta$ cells, which also had extremely significant difference $(P<0.01)$. The spindle in Dnm1 1 cells eventually elongated with a delayed fracture by over $7 \mathrm{~min}$ compared to wild type cells (Figs. 2D), indicating that Dnm1 not only plays an established role in spindle elongation in anaphase, but also participates in the late extension of the spindle. Cell length analysis of wild type cells and $D n m 1 \Delta$ cells showed that the cell length of wild type cells at spindle formation point, prophase and metaphase critical point, metaphase and anaphase critical point, anaphase and telophase critical point and the end point of mitosis were $12.86 \pm 1.30,12.99 \pm 1.23,13.22 \pm 1.26,13.40 \pm 1.25$ and $8.46 \pm 1.07$ $\mu \mathrm{m}$, respectively, while the cell length of Dnm1 $\Delta$ cells were $14.36 \pm 1.72,14.55 \pm 1.66,14.78 \pm 1.65,14.99$ \pm 1.69 and $8.62 \pm 0.81 \mu \mathrm{m}$, respectively (Figs. 2G-2K). Except for the cell length at the end of mitosis, there was a significant difference in cell length between the two groups (Figs. 2F).

\section{The effect of Dnm1 gene deletion on the spindle and chromosome in the prophase and metaphase of cell mitosis}

Firstly, the dynamic changes of spindles and chromosomes in prophase and metaphase were analyzed. The spindle of wildtype cells usually elongates at $0.23 \pm 0.09 \mu \mathrm{m} / \mathrm{min}$ during prophase, with duration of prophase of $3.80 \pm 1.01 \mathrm{~min}$ to reach a steady-state metaphase, and the spindle of wild-type cells usually elongates at $0.13 \pm 0.05 \mu \mathrm{m} / \mathrm{min}$ during metaphase with duration of metaphase of $14.75 \pm 3.43 \mathrm{~min}$. In contrast, the spindle of $D n m 1 \Delta$ cells elongates at $0.21 \pm 0.08 \mu \mathrm{m} / \mathrm{min}$ during prophase, with duration of prophase of $4.65 \pm 0.99 \mathrm{~min}$ to reach a steady-state metaphase, and the spindle of $D n m 1 \Delta$ cells usually elongates at $0.12 \pm 0.05 \mu \mathrm{m} / \mathrm{min}$ during metaphase with duration of metaphase of $15.90 \pm 2.88 \mathrm{~min}$ (Figs. 3A-3E). Studies have shown that there is a significant correlation between the intensity of the fluorescent protein and gene expression level, and the fluorescent intensity can indirectly reflect the 
expression level of the gene at the other end of the sequence connecting it (Grignani et al. 1998). The statistical results of chromosome fluorescence intensity at prophase and metaphase showed that there were no difference between wild type and $D n m 1 \Delta$ cells, while the statistical results of the fluorescence intensity of the spindle at prophase and metaphase showed that the fluorescence intensity of the spindle in Dnm1 $1 \Delta$ cells were higher than that in the wild type cells (Figs. 3F and 3G). At the same time, the structure and dynamics of the spindle microtubules were different in Dnm1 $1 \Delta$ cells compared with wild type. In wild type cells, mitosis and microtubule disintegration occurred simultaneously. In order to standardize the measurement of mitotic time, we defined the mitotic initiation time of 0 minute as the complete disintegration of cytoplasmic interphase microtubules. In wild type, time 0 min was consistent with the assembly of a microtubule "bar" ( $82.67 \pm 6.63 \%$ of cells) or a "dot" ( $17.33 \pm 5.77 \%$ of cells) that quickly transitions into a bar $(n=20)$, representing the bipolar spindle. In contrast, only $43.33 \pm 2.88 \%$ of Dnm $1 \Delta$ cells exhibited bars at time $0 \mathrm{~min}$. The rest exhibited delayed bipolar spindle formation, where the spindle dot occurred more frequently $(21.67 \pm 5.77 \%$ of cells) and took longer to form bars. Of interest, $35.00 \pm 5.00 \%$ of Dnm1 1 cells formed transient microtubule protrusions defined as monopolar spindle (mono) (Figs. 3H and 3l). There was no monopolar spindle in wild type cells. The results showed that Dnm1 gene deletion affected the organization and dynamics of spindle microtubules.

\section{The effect of Dnm1 gene deletion on spindles and chromosomes in the anaphase of cell mitosis}

The mC-Atb2 and Hht2-GFP were also used as the detection signals of anaphase to monitor spindle elongation and chromosome segregation during mitosis. The spindle of wild-type cells usually elongates at $0.56 \pm 0.07 \mu \mathrm{m} / \mathrm{min}$ at anaphase, with duration time of anaphase of $16.05 \pm 2.26 \mathrm{~min}$. In contrast, the spindle of $D n m 1 \Delta$ cells usually elongates at $0.50 \pm 0.08 \mu \mathrm{m} / \mathrm{min}$ at anaphase, with duration time of anaphase of $21.85 \pm 3.88 \mathrm{~min}$ (Figs. 4A-4C). Both values were also significantly different between wild type and $D n m 1 \Delta$ cells, and duration time of anaphase of wild-type were extremely significant longer than $D n m 1 \Delta$ cells, which showed that there was delayed spindle breakage in $D n m 1 \Delta$ cells. Chromosome segregation is an important cellular process and requires absolute fidelity, because errors would lead to developmental defects and diseases. The fidelity of chromosome segregation depends largely on the correct attachment of metaphase kinetochore and MT in metaphase. Chromosome segregation requires the assembly of spindles, which are based on microtubule (MT) structure and can effectively capture and separate sister chromatids during mitosis. The minus end of MT converges to the spindle pole, while the plus end of MT diverges from the opposite pole interdigitation in the middle of spindle. Mutations that alter the length of metaphase stable spindles are associated with chromosome segregation defects. Two different kinds of chromosome behaviors were observed: normal, the chromosome separate to opposite poles at anaphase; lagging, the chromosome is mis-separate to one pole but eventually corrected and separated to opposite poles (Fig. 4D). In Dnm1 $1 \Delta$ wild-type cells, the spindle breaked in the form of lineartype $(29.33 \pm 4.66 \%)$, arch-type $(41.67 \pm 6.41 \%)$ and S-type $(29.00 \pm 5.66 \%)$, but in wild-type cells, there were only linear-type and arch-type, and the percentage of the two form were $49.67 \pm 4.66 \%$ and $53.33 \pm$ $6.44 \%$, respectively(Figs. 4E and 4F). The results showed that the loss of Dnm1 gene could lead to abnormal spindle breakage. 


\section{The effect of Dnm1 gene deletion on coenzyme in energy metabolism}

Tricarboxylic acid cycle, oxidative phosphorylation pathway and glycolysis pathway are the main pathways of cell energy production. In order to further understand the energy metabolism of $D n m 1 \Delta$ cells, the coenzyme and the energy metabolites in these process were detected by LC-MS. The results showed that the relative contents of flavin mononucleotide (FMN), nicotinamide adenine dinucleotide (NAD+), nicotinamide-adenine dinucleotide phosphate (NADP+), thiamine pyrophosphate (TPP) and acetyl coenzyme A (acetyl-CoA) in wild-type cells were $20.11 \pm 0.31,25.85 \pm 0.08,23.44 \pm 0.37,22.87 \pm 0.18$ and $19.68 \pm 0.50$, respectively, and those in Dnm1 $\Delta$ cells were $19.98 \pm 0.01,25.94 \pm 0.10,15.66 \pm 0.22,23.24 \pm$ 0.18 and $18.82 \pm 0.27$, respectively, which had no significant difference between these two groups (Figs. 5A-5E). It was worth noting that the relative contents of nicotinamide adenine dinucleotide phosphate (NADPH) in wild-type cells was $16.37 \pm 0.26$, while the relative content of NADPH in Dnm1 cells was $15.66 \pm 0.22$ (Fig. 5 F), which had significant difference $(P<0.05)$.

\section{The effect of Dnm1 gene deletion on intermediates of energy metabolism}

The analysis of intermediate products of energy metabolism indicated that there were some abnormalities after the deletion of the Dnm 1 gene. The relative contents of D-glucose 6-phosphate, $\beta$-Dfructose 6-phosphate, citrate, and cis-aconitate in the wild type cells were $21.9 \pm 0.12,21.19 \pm 0.14,23.40$ \pm 0.33 and $18.40 \pm 0.15$, respectively, while those in Dnm1 $\Delta$ cells were $20.79 \pm 0.06,20.25 \pm 0.21,21.41 \pm$ 0.17 and $16.51 \pm 0.16$, respectively (Figs. 6A-6D), which were extremely significantly reduced in Dnm1 $\Delta$ cells $(P<0.01)$. The relative contents of pyruvate, isocitrate, and L-malic acid in the wild type cells were $14.07 \pm 0.33,17.17 \pm 0.40$ and $23.55 \pm 0.47$, respectively, while those in Dnm1 $\Delta$ cells were $13.24 \pm 0.33$, $15.95 \pm 0.21$ and $22.15 \pm 0.20$ in $D n m 1 \Delta$ cells, respectively, which were significantly reduced in $D n m 1 \Delta$ cells $(P<0.05)$ (Figs. 6E-6G). Although the relative contents of lactate, D-fructose 1,6-bisphosphate, phosphoenolpyruvate, dihydroxyacetone phosphate, oxaloacetate, a-ketoglutarate, succinate and fumarate were not significantly different in $D n m 1 \Delta$ cells compared with wild type cells, the relative contents of those intermediates in Dnm1 $1 \Delta$ cells was slightly lower than in the wild type cells (Figs. $6 \mathrm{H}$ 60). The above results suggested that the deletion of $\mathrm{Dnm} 1$ will affect the production of intermediates in energy metabolism.

\section{The effect of Dnm1 gene deletion on energy in energy metabolism}

The ultimate result of cell energy metabolism is to provides energy for cell growth and division. The results showed that the relative contents of adenosine triphosphate (ATP), adenosine diphosphate (ADP), adenosine monophosphate (AMP), guanosine triphosphate (GTP), guanosine diphosphate (GDP) and guanosine monophosphate (GMP) in the wild type cells were $21.02 \pm 0.17,24.79 \pm 0.41,26.35 \pm 0.12$, $16.95 \pm 0.29,20.98 \pm 0.14$ and $25.07 \pm 0.27$, respectively, while those in the Dnm1 $\Delta$ cells were $20.21 \pm 0.40$, $24.85 \pm 0.24,26.39 \pm 0.02,17.06 \pm 0.03,21.41 \pm 0.21$ and $25.45 \pm 0.06$, respectively (Figs. 7A-7F). It was worth noting that the relative content of ATP in the Dnm1 $1 \Delta$ cells was significantly lower $(P<0.05)$ than that of wild-type cells. The results showed that loss of $D n m 1$ gene will affect ATP production. 


\section{Discussion}

Metaphase describes the stage of mitosis in which chromosomes are attached to and oriented to bipolar spindles for later segregation. Microtubules (MTS) and their associated kinesin play a central role in nuclear migration, polarity, sexual reproduction and cell division (Mogilner and Craig 2010). There are some abnormalities in $D n m 1 \Delta$ cells. The binding of mitochondria to microtubules physically blocks the assembly of $D n m 1$ around mitochondria, thus inhibiting the division of mitochondria (Mehta et al. 2019). The interaction between microtubules and mitochondria, directly or indirectly through $D n m 1$, not only changes the arrangement of mitochondria, but also changes the behavior of microtubules. In $S$. cerevisiae, inactivation of Dnm1p prevented the fission of mitochondria, and the mitochondria formed a highly interconnected tubule network. Interestingly, the mitochondrial phenotypes of fragments in Dnm1, $m g m 1$ or Ugo 1 mutants, and the interconnected mitochondrial phenotypes in Dnm1 $1 \Delta$ cells can be alleviated when $D n m 1$ is inactivated with any of them. Dnm1, another DRP member of fission yeast, may cause epileptic encephalopathy (von Spiczak et al. 2017).

Spindle length statistics showed that there was delayed spindle breakage in $D n m 1 \Delta$ cells. At the same time, spindle microtubule organization has abnormal situations in Dnm $1 \Delta$ cells compared with wild type cells. The metaphase spindle length is thought to be regulated by the balance of pushing and pulling produced by different spindle microtubules (MTS) and their interactions with motor and MT associated proteins (MAPs (Microtubules associated proteins)). Spindle length is of great importance to the fidelity of chromosome segregation, because cells shorter or longer than normal metaphase spindles produced by deleting or inhibiting a single mitotic motor or MAPs showed chromosome segregation defects (Dumont and Mitchison 2009). But it is not involved the deletion or inhibition of individual mitotic motors or MAPs in our research. Therefore, we have reason to believe that the loss of $D n m 1$ gene from mitochondria could resulted in mitochondrial dynamics deficiency which will also contribute to the spindle maintenance deficiency and could lead to abnormal spindle breakage in the anaphase.

Mitochondria generate ATP through oxidative phosphorylation, and also have a central role in apoptosis (Jeong and Seol 2000; Marchenko et al. 2000; Karbowski 2010; Citi et al. 2018). Abnormal mitochondrial division and fusion are likely to lead to energy deficiencies and ultimately to changes in cell dynamics. If fission is not controlled and balanced by fusion, the network of mitochondria becomes too fragmented which leads to glucose oxidation, mitochondrial inner membrane potential decline, leading to the downregulation of ATP production (Bartolák-Suki et al. 2017). In the process of energy production in mitochondria, the abnormality of coenzyme or intermediate metabolite is likely to lead to the cell dysfunction. NADPH, mainly as a coenzyme of dehydrogenase, plays a role as a transmitter in oxidative phosphorylation and participates in a variety of anabolic reactions, such as the synthesis of lipids, fatty acids and nucleotides (Cave et al. 2006), and also regulates human cardiovascular diseases and pathophysiological processes, such as endothelial dysfunction, inflammation, hypertrophy, cell apoptosis, migration, angiogenesis and vascular and cardiac remodeling (Guzik et al. 2000; Heymes et al. 2003). The NADPH production was significantly reduced compared with wild-type cells, suggesting that Dnm1 gene deletion affected the hydrogen transfer of NADPH and the oxidative phosphorylation process. At the 
same time, the production of intermediates of energy metabolism showed abnormal situations in Dnm $1 \Delta$ cells. The production of D-glucose 6-photosphate, $\beta$-D-fructose 6-photosphate, citrate and cis-aconitate, decreased extremely significantly $(P<0.01)$, and pyruvate, isocitrate and L-malic acid decreased significantly $(P<0.05)$. The production of D-glucose 6-phosphate and $\beta$-D-Fructose 6-phosphate, which appeared in the speed limiting step of glycolysis (Jojima and Inui 2015), are significantly reduced, suggesting that $D n m 1$ gene deletion affected the key steps of glycolysis and further affects the speed of glycolysis. Pyruvate is the final product of glycolysis, and is finally imported into mitochondria as the main fuel of the tricarboxylic acid cycle. In mitochondria, pyruvate drives ATP production through a variety of biosynthetic pathways that intersect oxidative phosphorylation and the tricarboxylic acid cycle (Gray et al. 2014). In addition, pyruvate also plays an important role in the metabolism of three major nutrients (Owen et al. 2002). Abnormal metabolism of pyruvate plays an important role in cancer, heart failure and neurodegeneration (Gray et al. 2014). Compared with wild type, pyruvate decreased significantly in Dnm1 $1 \Delta$ cells, suggesting that $D n m 1$ gene deletion can reduce the amount of pyruvate and affect ATP production and metabolism of three major nutrients. Citrate, cis-aconitate, isocitrate and Lmalic acid the important intermediates to enter the tricarboxylic acid cycle, in which citrate 1 is the product of the first speed limiting step and plays a role of speed limiting. Citrate 1 also plays a role of lens plasma for eyes, bones and sperm (Akram 2014). Isocitrate helps to avoid wheezing and failure of automatic resuscitation under pathological conditions (Rivera-Angulo and Peña-Ortega 2014). L-malic acid is involved in the fourth redox in the tricarboxylic acid cycle, plays a role in promoting the capacity of the tricarboxylic acid cycle (Srere 1975), plays a role in protecting myocardial ischemia/reperfusion injury, anti-inflammatory and anti-latelet aggregation (Tang et al. 2013). Citrate1, cis-aconitate and isocitrate, Lmalic acid decreased significantly suggesting that $D n m 1$ gene deletion may affect the related links in the tricarboxylic acid cycle pathway and further affect energy productivity.

It has been reported that mitochondrial energy production is vital for cell division in addition to other basic functions in the cell, including the regulation of cell volume, cellular architectureand solute concentration (Sweet and Singh 1999). Energy levels differ at various stages of the cell cycle suggesting that there is a relationship between the abundance of energy and the cell's ability to enter a new cell cycle, which supported the hypothesis that mitochondria play a key role in cell cycle regulation (Harbauer et al. 2014; Lopez-Mejia and Fajas 2015). Although the specific mechanisms between mitochondria and the cell cycle regulation is not well understood, studies have shown that low energy cell cycle checkpoints monitor the energy capability before committing to another round of cell division. There are reports showed that the abnormal mitochondrion division and fusion will make the mitochondrial network become too scattered, which lead to the deficiency of ATP production (Bartolák-Suki et al. 2017). In our experiment, the results of effect of $D n m 1$ gene deletion on energy in energy metabolism showed that the relative content of Adenosine 5'-triphosphate (ATP) in the Dnm1 $\Delta$ cells were significant lower $(P<0.05)$ than those in wild type cells. It is suggested that $D n m 1$ gene deletion had significant effect on ATP production of cells.

Our experiment results indicated that the loss of $D n m 1$ gene from mitochondria resulted in spindle maintenance deficiency, chromosome segregation deficiency, spindle breakage deficiency, coenzyme 
deficiency, intermediate metabolite deficiency and ATP production deficiency.

\section{Declarations}

\section{Financial support and sponsorship}

This project was supported by the Science and Technology Support Project of Nanchong science and Technology Bureau of Sichuan Province (20YFZJ0053 and 20YFZJ0054), the Open Project Program of Irradiation Preservation Technology Key Laboratory of Sichuan Province, Sichuan Institute of Atomic Energy (FZBC2020009).

\section{Author contributions}

This study was designed and conceived by Yiling Hou. The experimental procedures and data analysis were carried out by Xiumei Tan, Xiang Ding and Yiling Hou. The manuscript was prepared by Xiumei Tan, Xiang Ding, Rongmei Yuan and Yiling Hou. All authors read and approved the final manuscript.

\section{Availability of data and materials}

The datasets used and/or analyzed during the current study are available from the corresponding author on reasonable request.

\section{Conflicts interest}

No competing financial interests exist.

\section{References}

1. Akram M (2014) Citric Acid Cycle and Role of its Intermediates in Metabolism. Cell Biochem Biophys 68:475-478. https://doi.org/10.1007/s12013-013-9750-1

2. Bartolák-Suki E, Imsirovic J, Nishibori Y, Krishnan R, Suki B (2017) Regulation of Mitochondrial Structure and Dynamics by the Cytoskeleton and Mechanical Factors. Int J Mol Sci 18: 1812 https://doi.org/103390/ijms18081812

3. Berkovic SF, Andermann F, Shoubridge EA, Carpenter S, Robitaille Y, Andermann E et al (1991) Mitochondrial dysfunction in multiple symmetrical lipomatosis. Ann Neurol 29: 566-569. https://doi.org/101002/ana410290519

4. Bertholet AM, Delerue T, Millet AM, Moulis MF, David C, Daloyau M et al (2016) Mitochondrial fusion/fission dynamics in neurodegeneration and neuronal plasticity. Neurobiol Dis 90: 3-19. https://doi.org/101016/jnbd201510011

5. Bleazard W, McCaffery JM, King EJ, Bale S, Mozdy A, Tieu Q (1999) The dynamin-related GTPase Dnm1 regulates mitochondrial fission in yeast. Nat Cell Biol 1: 298-304. https://doi.org/101038/ncb0999_298 
6. Burté F, Carelli V, Chinnery PF, Yu-Wai-Man P (2014) Disturbed mitochondrial dynamics and neurodegenerative disorders. Nature Rev Neurol 11: 11-24. https://doi.org/101038/nrneurol2014228

7. Cave AC, Brewer AC, Narayanapanicker A, Ray R, Shah AM (2006) NADPH oxidases in cardiovascular health and disease. Antioxid Redox Signal 8: 691-728. https://doi.org/101089/ars20068691

8. Chang CR, Manlandro CM, Arnoult D, Stadler J, Posey AE, Hill RB et al (2010) A lethal de novo mutation in the middle domain of the dynamin-related GTPase Drp1 impairs higher order assembly and mitochondrial division. J Biol Chem 285: 32494-32503.

https://doi.org/101074/jbcM110142430

9. Chen L, Winger AJ, Knowlton AA (2014) Mitochondrial dynamic changes in health and genetic diseases. Mol Biol Rep 41: 7053-7062 https://doi.org/101007/s11033-014-3663-y

10. Citi V, Calderone V, Martelli A, Breschi MC, Testai L (2018) Pathophysiological Role of Mitochondrial Potassium Channels and their Modulation by Drugs. Curre Med Chem 25: 2661-2674. https://doi.org/102174/0929867324666171012115300

11. Delerue T, Tribouillard-Tanvier D, Daloyau M, Khosrobakhsh F, Emorine LJ, Friocourt G et al (2019) A yeast-based screening assay identifies repurposed drugs that suppress mitochondrial fusion and mtDNA maintenance defects Dis Model Mech 12: dmm036558 https://doi.org/101242/dmm036558

12. Dumont S, Mitchison TJ (2009) Force and Length in the Mitotic Spindle. Curr Biol 19: R749-R761 https://doi.org/101016/jcub200907028

13. Forsburg SL, Rhind N (2006) Basic methods for fission yeast Yeast. 23: 173-183. https://doi.org/101002/yea1347

14. Francy CA, Alvarez FJD, Zhou L, Ramachandran R, Mears JA (2015) The Mechanoenzymatic Core of Dynamin-related Protein 1 Comprises the Minimal Machinery Required for Membrane Constriction. J Biol Chem 290:11692-11703. https://doi.org/101074/jbcm114610881

15. Gao J, Wang L, Liu J, Xie F, Su B, Wang X (2017) Abnormalities of Mitochondrial Dynamics in Neurodegenerative Diseases. Antioxidants 6: 25-43. https://doi.org/103390/antiox6020025

16. Goshima G, Scholey JM (2010) Control of mitotic spindle length. Annu Rev Cell Dev Biol 26: 21-57. https://doi.org/101146/annurev-cellbio-100109-104006

17. Gray LR, Tompkins SC, Taylor EB (2014) Regulation of pyruvate metabolism and human disease. Cell Mol Life Sci 71:2577-2604

18. Grignani F, Kinsella T, Mencarelli A, Valtieri M, Riganelli D, Grignani F et al (1998) High-efficiency gene transfer and selection of human hematopoietic progenitor cells with a hybrid ebv/retroviral vector expressing the green fluorescence protein. Cancer Res 58: 14-19. https://doi.org/101111/cccr12130

19. Guzik TJ, West NEJ, Black E, McDonald D, Ratnatunga C, Pillai R et al (2000) Vascular superoxide production by $N A D(P) H$ oxidase: association with endothelial dysfunction and clinical risk factors. Circ Res 86: E85-E90. https://doi.org/103109/00365515109060625

20. Harbauer AB, Opalińska M, Gerbeth C, Herman JS, Rao S, Schönfisch B (2014) Mitochondria cell cycle-dependent regulation of mitochondrial preprotein translocase. Science 346: 1109-1113. https://doi.org/101126/science1261253 
21. Heymes C, Bendall JK, Ratajczak P, Cave AC, Samuel JL, Hasenfuss G et al (2003) Increased myocardial NADPH oxidase activity in human heart failure. J Am Coll Cardiol 41: 2164-2171 https://doi.org/101016/s0735-1097(03)00471-6

22. Huber N, Guimaraes S, Schrader M, Suter U, Niemann A (2013) Charcot-Marie-Tooth diseaseassociated mutants of GDAP1 dissociate its roles in peroxisomal and mitochondrial fission. EMBO Rep 14: 545-552. https://doi.org/101038/embor201356

23. Jeong SY, Seol DW (2000) The role of mitochondria in apoptosis. BMB Rep 35: 11-22. https://doi.org/105483/BMBRep2008411011

24. Jojima T, Inui M (2015) Engineering the glycolytic pathway: a potential approach for improvement of biocatalyst performance. Bioengineered 6: 328-334.

https://doi.org/101080/2165597920151111493

25. Jourdain I, Gachet Y, Hyams JS (2010) The dynamin related protein Dnm1 fragments mitochondria in a microtubule-dependent manner during the fission yeast cell cycle. Cell Motil Cytoskelet 66: 509523. https://doi.org/101002/cm20351

26. Karbowski M (2010) Mitochondria on Guard: Role of Mitochondrial Fusion and Fission in the Regulation of Apoptosis. Adv Exp Med Biol 687: 131-142. https://doi.org/101007/978-1-4419-6706$0 \_8$

27. Karren MA, Coonrod EM, Anderson TK, Shaw JM (2005) The role of fis1p-mdv1p interactions in mitochondrial fission complex assembly. J Cell Biol 171: 291-301. https://doi.org/101083/jcb200506158

28. Kim Y, Vadodaria KC, Lenkei Z, Kato T, Gage FH, Marchetto MC et al (2019) Mitochondria Metabolism and Redox Mechanisms in Psychiatric Disorders. Antioxid Redox Signal 31: 275-317. https://doi.org/101089/ars20187606

29. Kuravi K, Nagotu S, Krikken AM, Sjollema K, Deckers M, Erdmann R et al (2006) Dynamin-related proteins Vps1p and Dnm1p control peroxisome abundance in saccharomyces cerevisiae. J Cell Sci 119: 3994-4001. https://doi.org/101242/jcs03166

30. Lackner LL (2014) Shaping the dynamic mitochondrial network. BMC Biol 12: 35-45. https://doi.org/101186/1741-7007-12-35

31. Lopez-Mejia IC, Fajas L (2015) Cell cycle regulation of mitochondrial function. Curr Opin Cell Biol 33: 19-25. https://doi.org/101016/jceb201410006

32. Marchenko ND, Zaika A, Moll UM (2000) Death Signal-induced Localization of p53 Protein to Mitochondria. J Biol Chem 275: 16202-16212. https://doi.org/101074/jbc2752116202

33. Mears JA, Lackner LL, Fang S, Ingerman E, Nunnari J, Hinshaw JE (2011) Conformational changes in Dnm1 support a contractile mechanism for mitochondrial fission. Nat Struct Mol Biol 18: 20-26. https://doi.org/101038/nsmb1949

34. Mehta K, Chacko LA, Chug MK, Jhunjhunwala S, Ananthanarayanan V (2019) Association of mitochondria with microtubules inhibits mitochondrial fission by precluding assembly of the fission protein Dnm1. J Biol Chem 294: 3385-3396. https://doi.org/101074/jbcra118006799 
35. Mogilner A, Craig E (2010) Towards a quantitative understanding of mitotic spindle assembly and mechanics. J Cell Sci 123: 3435-3445. https://doi.org/101242/jcs062208

36. Naumann M, Kiefer R, Toyka KV, Sommer C, Seibel P, Reichmann H (1997) Mitochondrial dysfunction with myoclonus epilepsy and ragged-red fibers point mutation in nerve muscle and adipose tissue of a patient with multiple symmetric lipomatosis. Muscle Nerve 20: 833-839. https://doi.org/101002/ana410290519

37. Owen OE, Kalhan SC, Hanson RW (2002) The key role of anaplerosis and cataplerosis for citric acid cycle function. J Biol Chem 277: 30409-30412. https://doi.org/101074/jbcR200006200

38. Rivera-Angulo AJ, Peña-Ortega $F$ (2014) Isocitrate supplementation promotes breathing generation gasping and autoresuscitation in neonatal mice. J Neurosci Res 92: 375-388. https://doi.org/101002/jnr23330

39. Rongmei Y, Xiang D, Xiumei T, Yiling H (2020) Loss of FZO1 gene results in changes of cell dynamics in fission yeast. Int J Mole Med 46: 2194-2206 2020. https://doi.org/103892/ijmm20204752

40. Rousset Cl, Baburamani AA, Thornton C, Hagberg H (2012) Mitochondria and perinatal brain injury. J Matern Fetal Neonatal Med 25: 35-38 https://doi.org/103109/147670582012666398

41. Sajic M (2014) Mitochondrial Dynamics in Peripheral Neuropathies. Antioxid Redox Signal 21: 601620 https://doi.org/101089/ars20135822

42. Sheffer R, Douiev L, Edvardson S, Shaag A, Tamimi K, Soiferman D et al (2016) Postnatal microcephaly and pain insensitivity due to a de novo heterozygous DNM1L mutation causing impaired mitochondrial fission and function. Am J Med Genet A 170: 1603-1607. https://doi.org/101002/ajmga37624

43. Srere PA (1975) The enzymology of the formation and breakdown of citrate. Adv Enzymol Relat Areas Mol Biol 43:57-101. https://doi.org/10.1002/9780470122884.ch2

44. Sweet S, Singh G (1999) Changes in mitochondrial mass membrane potential and cellular adenosine triphosphate content during the cell cycle of human leukemic (hl-60) cells. J Cell Physiol 180: 91-96. https://doi.org/101002/(SICI)1097-4652(199907)180:1<91::AID-JCP10>30C0;2-6

45. Syrovatkina V, Fu C, Tran PT (2013) Antagonistic Spindle Motors and MAPs Regulate Metaphase Spindle Length and Chromosome Segregation. Currt Biol 23: 2423-2429 https://doi.org/101016/jcub201310023

46. Tang X, Liu J, Dong W, Li P, Li L, Lin C (2013) The cardioprotective effects of citric Acid and L-malic Acid on myocardial ischemia/reperfusion injury. Evid Based Complement Alternat Med 2013: 820695. https://doi.org/101155/2013/820695

47. Tieu Q, Okreglak V, Naylor K, Nunnari J (2002) The WD repeat protein Mdv1p functions as a molecular adaptor by interacting with dnm1p and fis $1 \mathrm{p}$ during mitochondrial fission. J Cell Biol 158: 445-452. https://doi.org/101083/jcb200205031

48. Tran PT, Paoletti A, Chang F (2004) Imaging green fluorescent protein fusions in living fission yeast cells. Methods 33: 220-225. https://doi.org/101016/jymeth200311017 
49. von Spiczak S, Helbig KL, Shinde DN, Huether R, Pendziwiat M, Lourenço C et al (2017) DNM1 encephalopathy: a new disease of vesicle fission. Neurology 89: 385-394. https://doi.org/101212/WNL0000000000004152

50. Zhao J, Lendahl U, Nistér M (2012) Regulation of mitochondrial dynamics: convergences and divergences between yeast and vertebrates. Cell Mol Life Sci 70: 951-976. https://doi.org/101007/s00018-012-1066-6

\section{Figures}



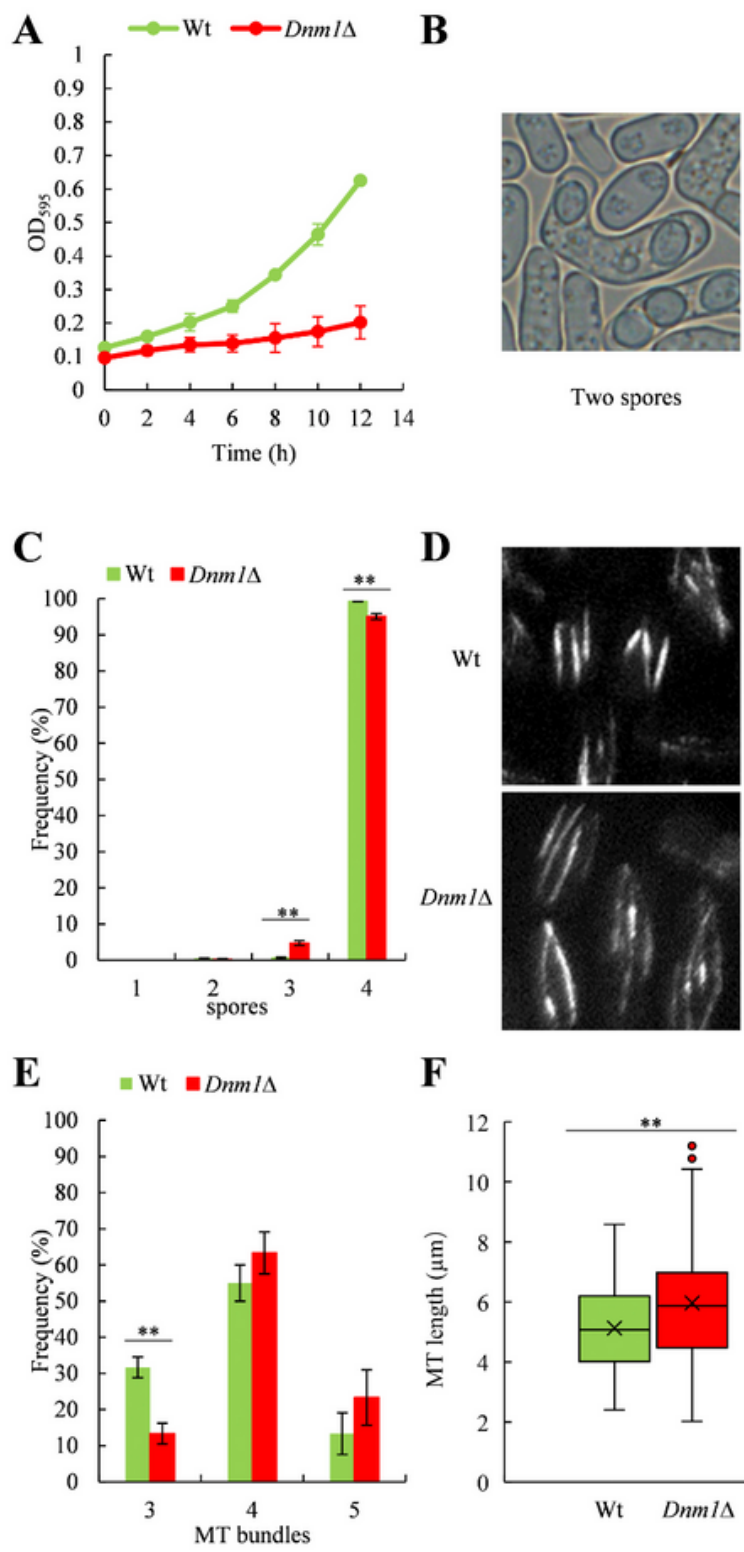

F
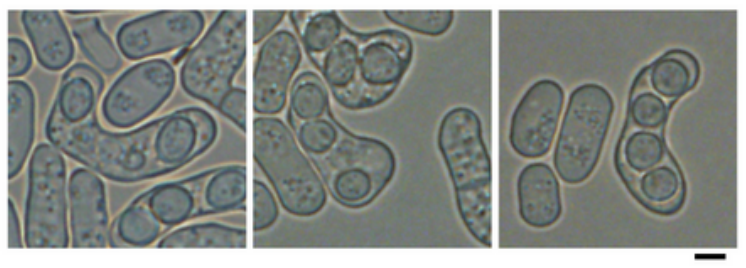

Two spores

Three spores

Four spores

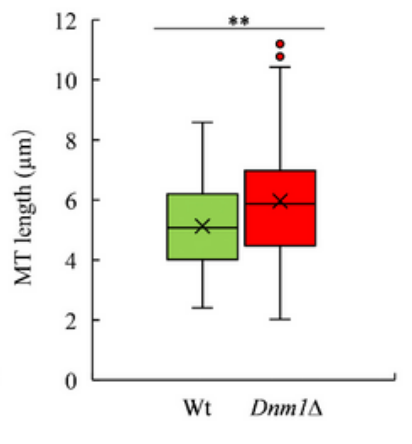

G
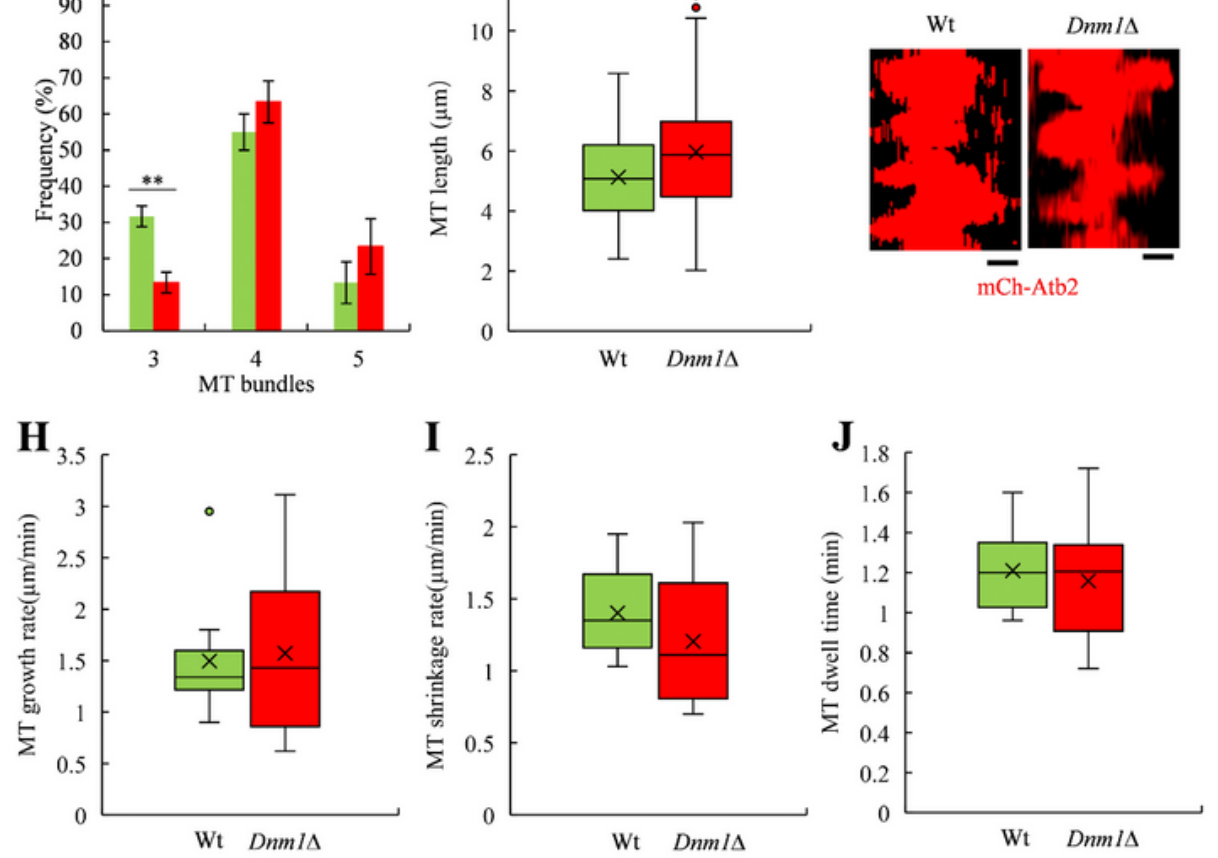

\section{Figure 1}

: The effect of Dnm1 gene deletion on the cell growth, morphology and number of microtubule and ascospores (A) The growth curves of Wt cells and Dnm1 $\Delta$ cells cultured at $25^{\circ} \mathrm{C}$. Notes: Data represented as mean $\pm S D$ ( $n=3$, the experiment was repeated three times). (B) Morphology results of ascospores in Dnm1 $\Delta$ cells. Scale bar: $5 \mu \mathrm{m}$. (C) Statistical analysis of spore number of wild type and Dnm1 $\Delta$ cells $(n=1500, n$ is the number of cells). Notes: Data represented as mean $\pm S D$. $* * P<0.01$. (D) Microtubule 
morphology of wild type and Dnm1 $\Delta$ cells in mitotic interphase. Scale bar: $5 \mu \mathrm{m}$. (E) Statistical analysis of the number of microtubules of wild type and Dnm $1 \Delta$ cells in the mitotic interphase $(n=20 ; n$ is the number of cells). Choose the time of 8 minutes in mitotic interphase as the observation time of microtubule morphology. Take the maximum number of microtubules in each cell as the final microtubules number, and the maximum microtubule length of each microtubule as the final microtubule length. Use the same VANILE ratio in FIJI to reduce the statistical error of fluorescent dye. Notes: Data represented as mean $\pm S D$. $* \star P<0.01$. (F) Statistical analysis of the length of wild type and $D n m 1 \Delta$ cells in the mitotic interphase ( $n=80 ; n$ is the number of microtubules). ${ }^{\star} P<0.01$. (G) Microtubule dynamics of wild type cells and Dnm $1 \Delta$ cells during mitotic interphase. Scale bar: $2 \mu \mathrm{m}$. $(H)$ Statistical analysis of MT growth rate in wild type and Dnm $1 \Delta$ cells ( $n=10, n$ is microtubule number). (I) Statistical analysis of MT shrinkage rate in wild type and $\operatorname{Dnm} 1 \Delta$ cells $(n=10, n$ is microtubule number). (J) Statistical analysis of MT dwell time in wild type and Dnm1 $\Delta$ cells ( $n=10, n$ is microtubule number). 
A

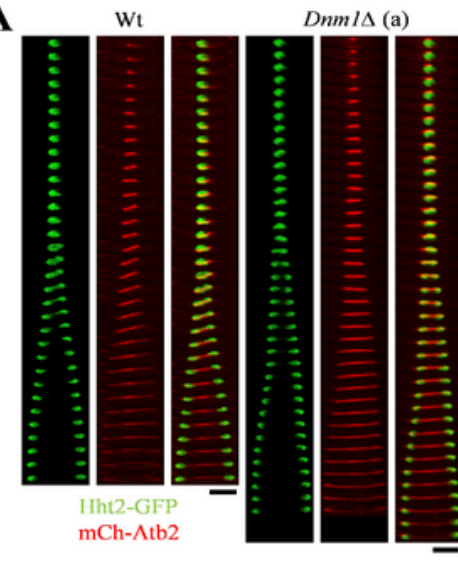

$D n m I \Delta$ (b)

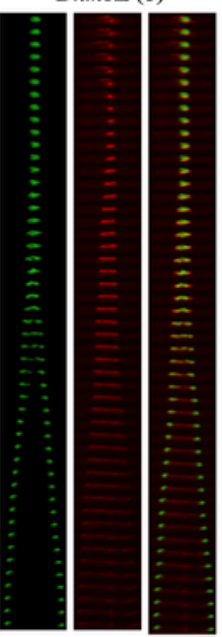

B
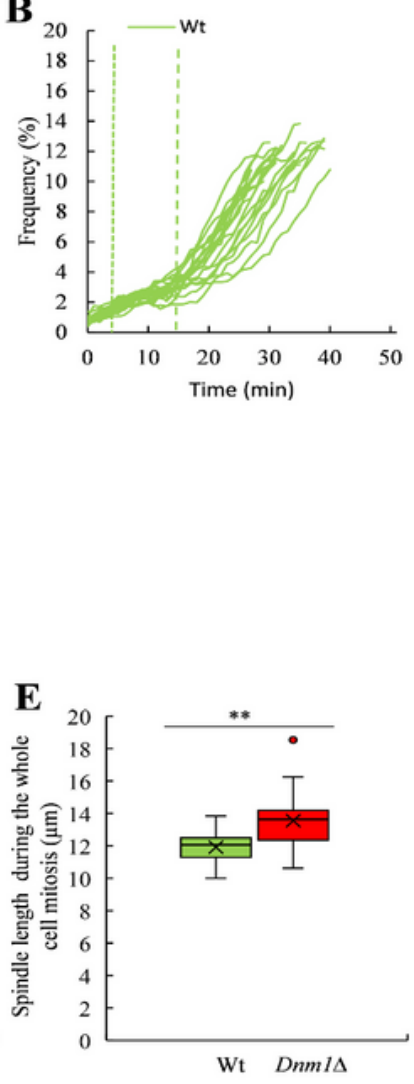

$\mathbf{H}$

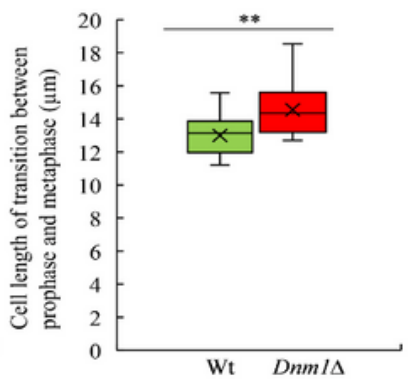

K

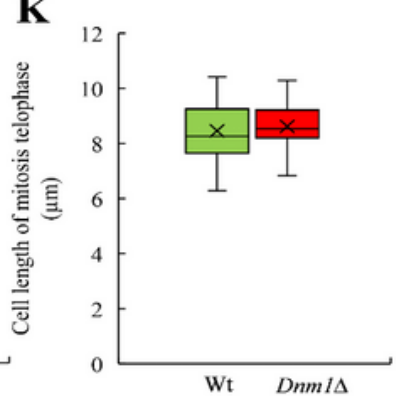

Figure 2

The effect of Dnm1 gene deletion on spindle and cell length during cell mitosis (A) Spindle and chromosome dynamics of wild type and Dnm1 $\Delta$ cells during the whole cell mitosis (chromosomes are marked by Hht2-GFP, spindles are marked by mCh-Atb2). a-b showed different abnormal situations in Dnm $1 \Delta$ cells. Scale bar: $5 \mu \mathrm{m}$. (B) Spindle elongation analysis of wild type during cell mitosis. $(n=20, n$ is the number of cells; The dotted line from left to right in the figure indicated the critical point between 
prophase and metaphase, metaphase and anaphase, respectively). (C) Spindle elongation analysis of Dnm1 $\Delta$ cells during cell mitosis. $(n=20, n$ is the number of cells; The dotted line from left to right in the figure indicated the critical point between prophase and metaphase, metaphase and anaphase, respectively). (D) Statistical analysis of the spindle elongation time of wild type and Dnm1 $\Delta$ cells during the whole cell mitosis ( $n=20, n$ is the cells number). ${ }^{* *} P<0.01$. (E) Statistical analysis of the spindle length of wild type and Dnm1 $\Delta$ cells during the whole cell mitosis ( $n=20, n$ is the cells number). ${ }^{\star *} P<0.01$. (F) Cell morphology results of wild type and Dnm1 $\Delta$ cells at spindle formation point, prophase and metaphase critical point, metaphase and anaphase critical point, anaphase and anaphase critical point and the end point of mitosis, respectively (chromosomes are marked by Hht2-GFP, spindles are marked by mCh-Atb2). Scale bar: $2 \mu \mathrm{m}$. The cell length analysis of wild type and Dnm1 $\Delta$ cells at the spindle forming point $(G)$, prophase and metaphase critical point $(H)$, metaphase and anaphase critical point $(I)$, anaphase and telophase critical point $(J)$ and the end point of mitosis $(K)$, respectively $(n=20, n$ is the cells number). ${ }^{\star *} \mathrm{P}<0.01$. 

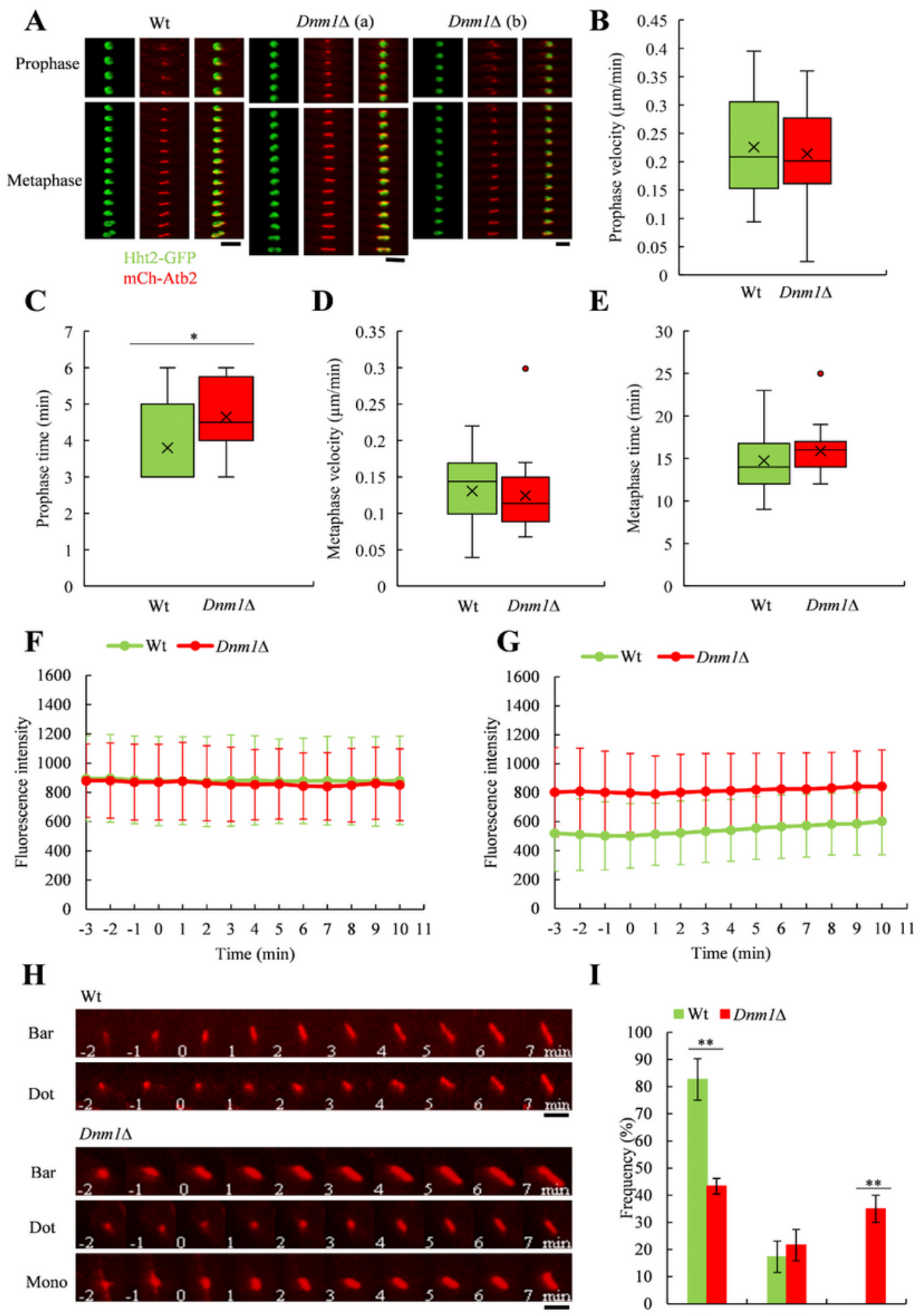

I

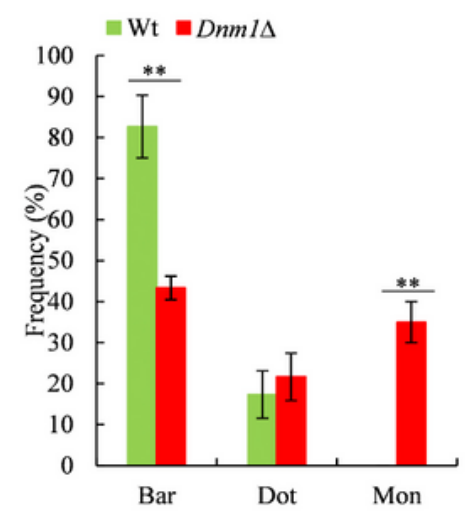

\section{Figure 3}

The effect of Dnm1 gene deletion on the spindle and chromosome in the prophase and metaphase of cell mitosis (A) Spindle and chromosome dynamics of wild type and Dnm1 $\Delta$ cells at prophase and metaphase (chromosomes are marked by Hht2-GFP, spindles are marked by mCh-Atb2). a-b showed different abnormal situations in Dnm1 $\Delta$ cells. Scale bar: $5 \mu \mathrm{m}$. (B) Statistical analysis of the spindle elongation rate of wild type and Dnm1 $\Delta$ cells at prophase ( $n=20, n$ is the cells number). (C) Statistical 
analysis of the spindle elongation time of wild type and Dnm1 $\Delta$ cells at prophase $(n=20, n$ is the cells number). ${ }^{*} P<0.05$. (D) Statistical analysis of the spindle elongation rate of wild type and Dnm1 $\Delta$ cells at metaphase ( $n=20, n$ is the cells number). (E) Statistical analysis of spindle elongation time of wild type and Dnm $1 \Delta$ cells at metaphase $(n=20, n$ is cells number) $(F)$ Statistical analysis of chromosome fluorescence intensity of wild type and Dnm $1 \Delta$ cells at prometaphase and metaphase $(n=20, n$ is cell number) ("0" is the critical point of prophase and metaphase). (G) Statistical analysis of spindle fluorescence intensity of wild type and Dnm1 $\Delta$ cells at prometaphase and metaphase $(n=20, n$ is cell number) ("O" is the critical point of prophase and metaphase). $(\mathrm{H})$ Morphology results of spindle formation types in wild type and Dnm1 $\Delta$ cells (time " 0 " min is the complete disassembly of cytoplasmic interphase microtubules). Scale bar: $2 \mu \mathrm{m}$. (I) Statistical analysis of spindle formation types in wild type and Dnm1 $\Delta$ cells $\left(n=20, n\right.$ is cell number). ${ }^{* *} P<0.01$. 
A

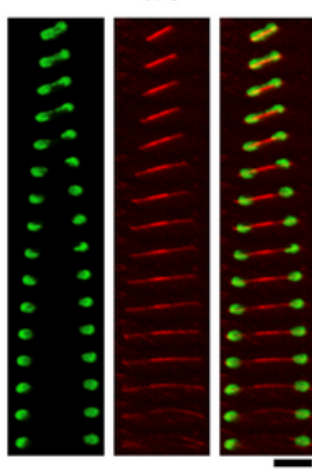

Hht2-GFP mCh-Atb2
$\operatorname{Dnm} 1 \Delta$ (a)
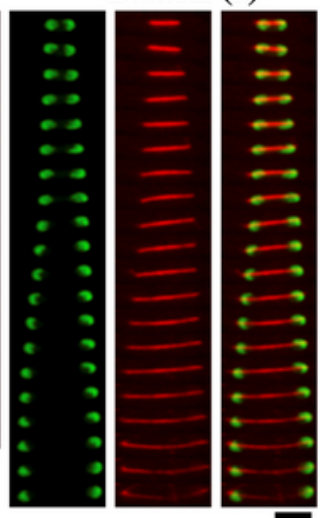

C

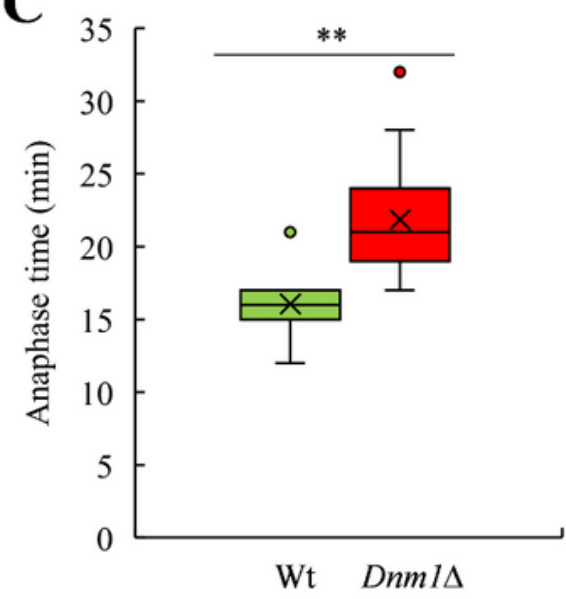

E

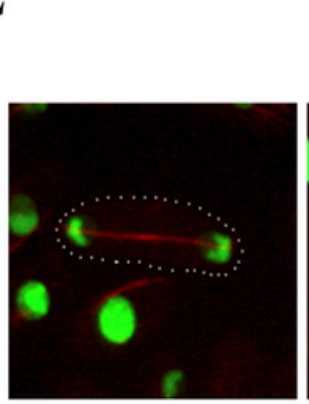

Linear-type
Hht2-GFP

mCh-Atb2

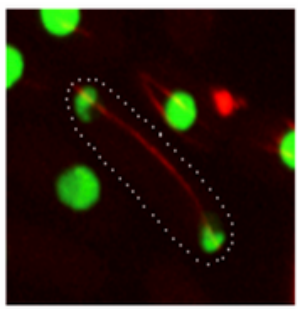

Arch-type

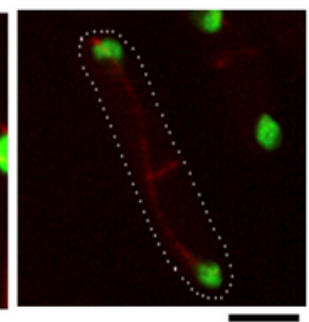

S-type
B

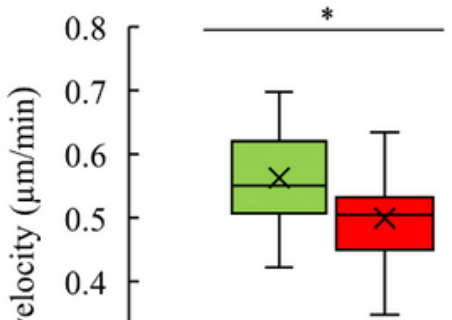

Hht2-GFP

mCh-Atb2

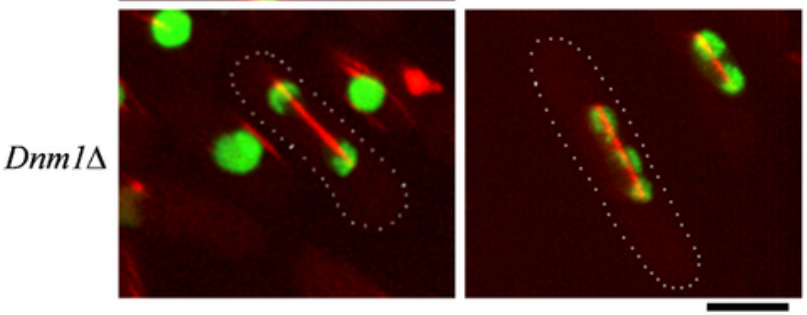

F

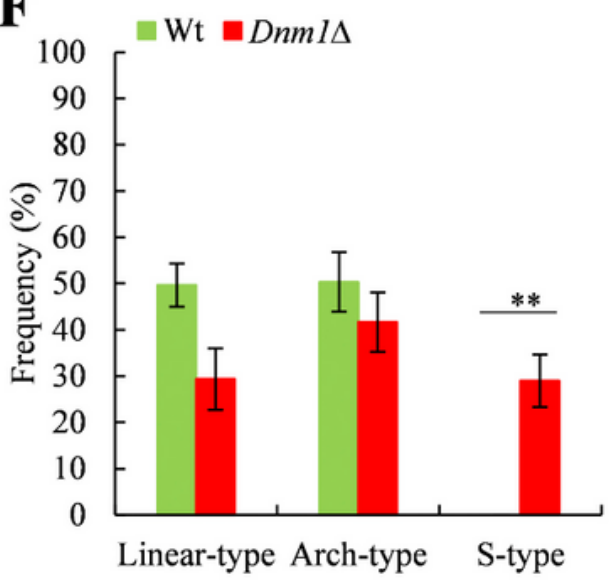

\section{Figure 4}

The effect of Dnm1 gene deletion on spindles and chromosomes in the anaphase of cell mitosis (A) Spindle and chromosome dynamics of wild type and Dnm1 $\Delta$ cells at anaphase (chromosomes are marked by Hht2-GFP, spindles are marked by mCh-Atb2). Scale bar: $5 \mu \mathrm{m}$. (B) Statistical analysis of the spindle elongation rate of wild type and $D n m 1 \Delta$ cells at anaphase ( $n=20, n$ is the cells number). * $P<0.05$. (C) Statistical analysis of the spindle elongation time of wild type and $\mathrm{Dnm} 1 \Delta$ cells at metaphase $(\mathrm{n}=20$, 
$\mathrm{n}$ is the cells number). ${ }^{*} \mathrm{P}<0.01$. (D) Morphology of chromosome segregation types of wild type and Dnm1 $\Delta$ cells at anaphase (chromosomes are marked by Hht2-GFP, spindles are marked by mCh-Atb2). Scale bar: $5 \mu \mathrm{m}$. (E) Morphology of spindle break types of wild type and Dnm1 $\Delta$ cells at anaphase (chromosomes are marked by Hht2-GFP, spindles are marked by mCh-Atb2). Scale bar: $5 \mu \mathrm{m}$. (F) Statistical analysis of spindle break types of wild type and Dnm1 $\Delta$ cells ( $n=20, n$ is the cells number). Notes: Data represented as mean $\pm \mathrm{SD}$. ${ }^{*} \mathrm{P}<0.01$.
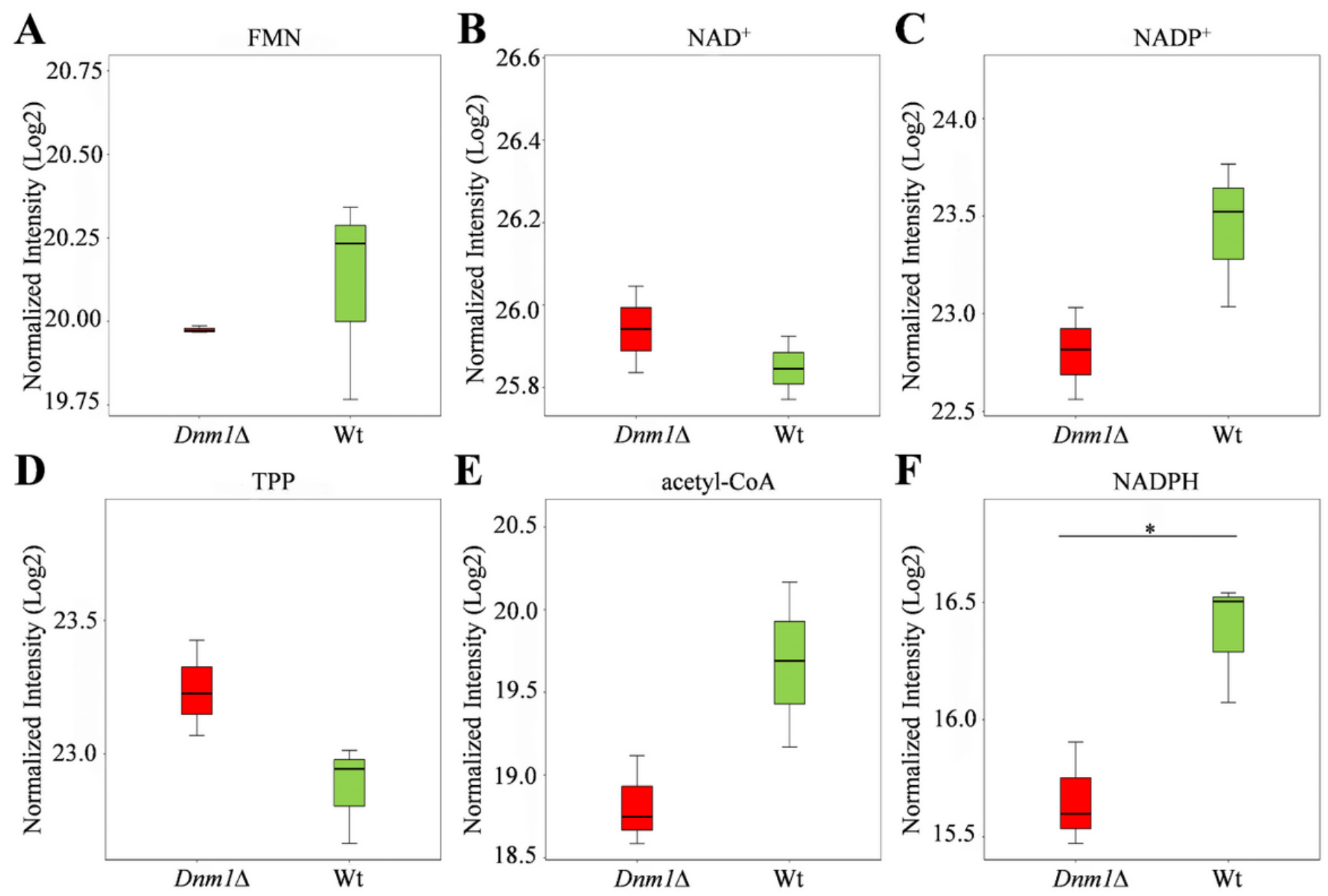

Figure 5

The effect of Dnm1 gene deletion on coenzyme in energy metabolism (A-F) Statistical analysis of relative contents of FMN, NAD+, NADP+, TPP, acetyl-CoA and NADPH in wild-type and Dnm1 $\triangle$ cells $(n=3$, the experiment was repeated three times). ${ }^{*} \mathrm{P}<0.05$. 

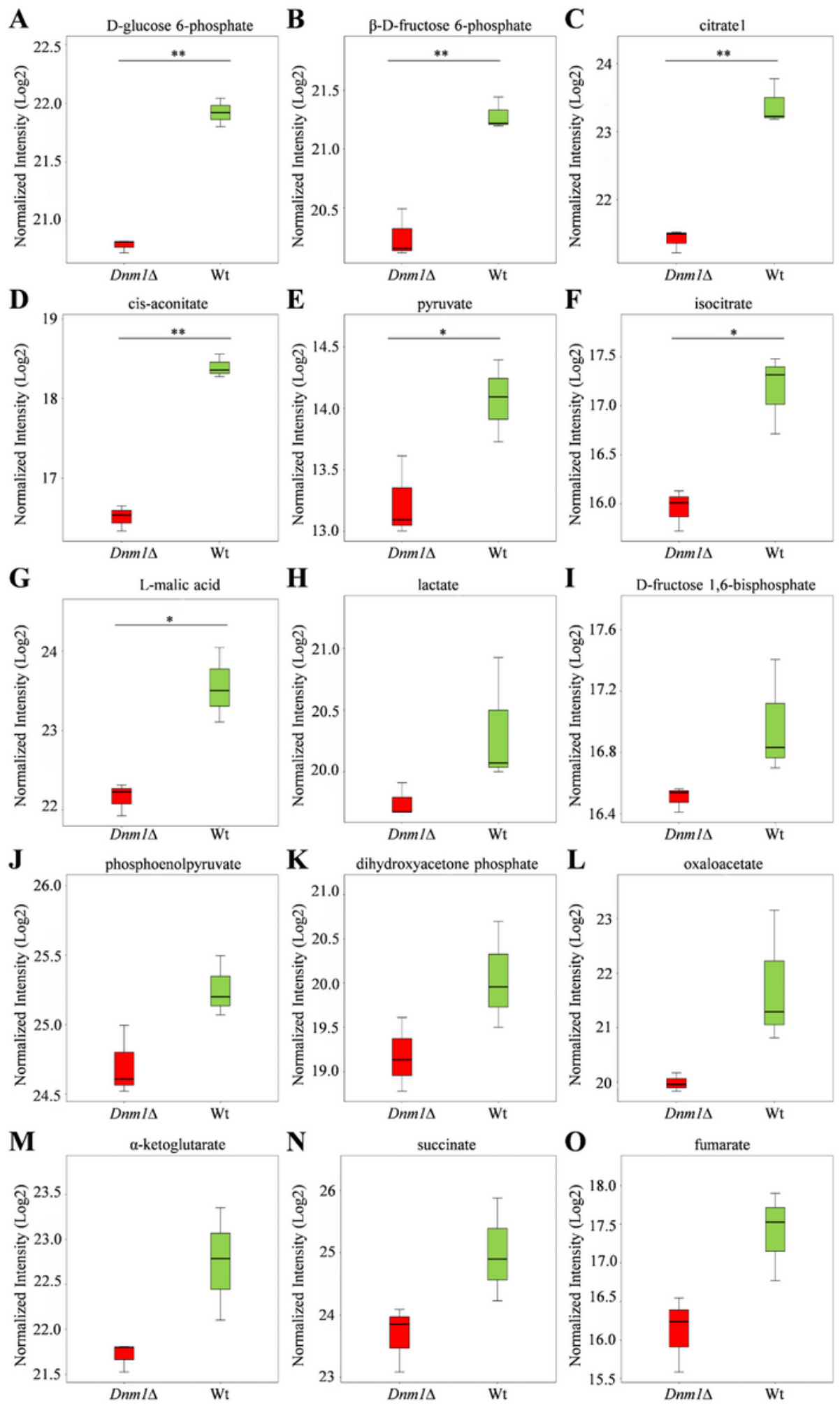

\section{Figure 6}

The effect of Dnm1 gene deletion on intermediates of energy metabolism (A-0) Statistical analysis of relative contents of D-glucose 6-phosphate, $\beta$-D-fructose 6-phosphate, citrate1, cis-aconitate, pyruvate, isocitrate, L-malic acid, lactate, D-fructose 1,6-bisphosphate, phosphoenolpyruvate, dihydroxyacetone, oxaloacetate, a-ketoglutarate, succinate and fumarate in wild-type and Dnm1 $\Delta$ cells $(n=3$, the experiment was repeated three times). ${ }^{*} \mathrm{P}<0.05$, ** $\mathrm{P}<0.01$. 

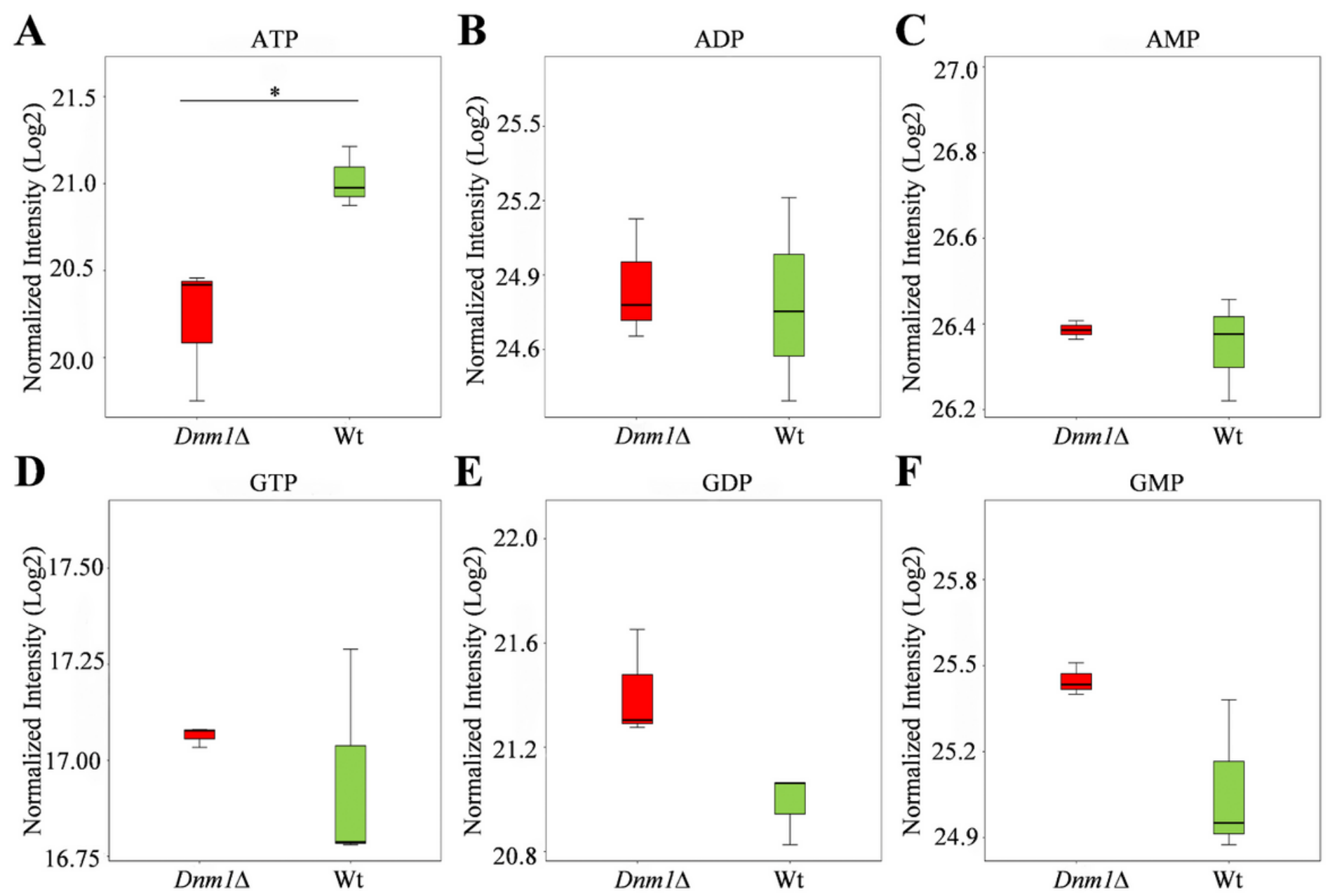

Figure 7

The effect of Dnm1 gene deletion on energy in energy metabolism (A-F) Statistical analysis of relative contents of ATP, ADP, AMP, GTP, GDP and GMP in wild-type and Dnm $1 \Delta$ cells $(n=3$, the experiment was repeated three times). * $P<0.05$. 